\title{
High Dynamic-Range and Very Low Noise K-Band p-HEMT LNA MMIC for LMDS and Satellite Communication
}

\author{
M. Hirata*, Y. Mimino, Y. Hasegawa and J. Fukaya
}

Fujitsu Quantum Devices Ltd.

\author{
Kokubo-Kogyo-Danchi, Showa, Nakakoma, Yamanashi 409-3883, JAPAN \\ *Fujitsu Compound Semiconductor, Inc. \\ 2355 Zanker Road, San Jose, CA 95131, USA, MHirata@fcsi.fujitsu.com
}

\section{Abstract}

An excellent noise figure and high linearity, K-band p-HEMT LNA MMIC, that incorporates single-bias configuration and negative feedback circuit, has been developed for LMDS (Local Multi-point Distribution Service) and satellite communication. The third order intercept point (IP3) of this MMIC is $20 \mathrm{dBm}$, while output power at 1-dB gain compression is 8.5 $\mathrm{dBm}$. The IP3 and noise figure is 19.5 $+/-1 \mathrm{dBm}$ and $1.8+/-0.2 \mathrm{~dB}$, respectively, at frequencies between 24 and $32 \mathrm{GHz}$. The die size of the MMIC is $1.9 \mathrm{~mm}^{2}$. This MMIC shows a potential reliable application in high-speed wireless access system.

\section{INTRODUCTION}

The design and manufacturing technologies of K-band low-noise amplifiers (LNAs) MMIC have been matured, and these MMICs are being commercially available. While modulation schemes for LMDS such as quadrature amplitude modulation (QAM), used to handle high capacity data transfer, requires these amplifiers should be high third-order intercept point [1].

This paper demonstrates a high linearity, 24-32 GHz LNA MMIC for LMDS and satellite communication.

\section{HEMT STRUCTUER} AND MMIC DESIGN

This LNA MMIC consists of 3-stages InGaP/InGaAs pseudomorphic HEMTs (p-HEMTs), which is fabricated on a semi-insulated GaAs substrate with $0.15-\mu \mathrm{m}$-long $\mathrm{T}$-shaped gate electrode [2], [3]. A schematic cross section of the HEMT is shown in Figure 1.

By using self-bias scheme, gate-bias circuit can be removed and insertion loss of biasing circuit is $0.2 \mathrm{~dB}$ lower than conventional circuits. The die size 
of the MMIC is reduced to $1.9 \mathrm{~mm}^{2}$ by means of minimized biasing circuit and high-impedance matching circuit [4], [5].

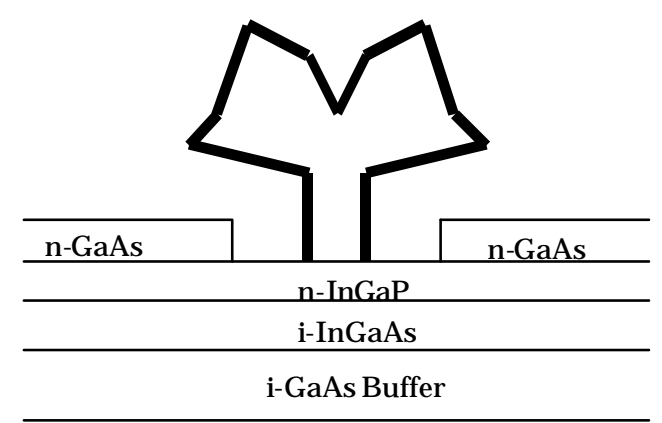

S.I.

GaAs

Figure 1 Schematic cross section of a T-shaped $0.15-\mu \mathrm{m}$ In G aP/InG aAs HE M T

The gate widths of first and second stages are $80 \mu \mathrm{m}$ and to increase output power, gate width of third stage is $160 \mu \mathrm{m}$. Matching condition of this MMIC, at first and second stage is matched for the minimum noise figure (NF) and that at final stage is matched for the gain and linearity. Microphotograph of the LNA MMIC $1.6 \times 1.2 \mathrm{~mm}^{2}$ in size is shown in Figure 2.

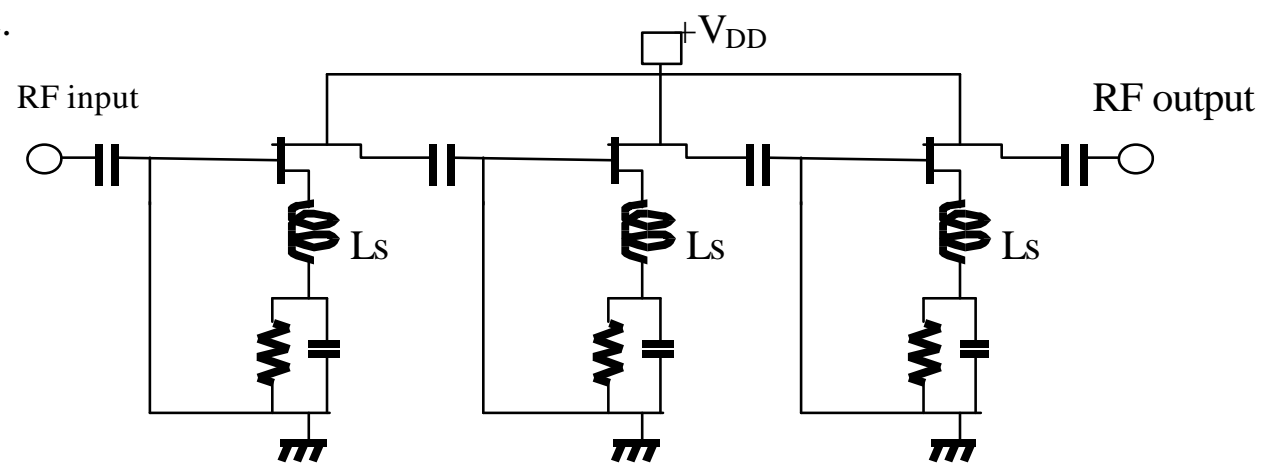

Figure 3. Circuit topology of the LNA MMIC Ls : Source Inductance 
As shown in this graph, noise figure is better than $2 \mathrm{~dB}$ from 24 to $32 \mathrm{GHz}$, and minimum $1.6 \mathrm{~dB}$ at $27 \mathrm{GHz}$. The associated gain is $24 \mathrm{~dB}$ at $24 \mathrm{GHz}$ and $18 \mathrm{~dB}$ at $32 \mathrm{GHz}$.

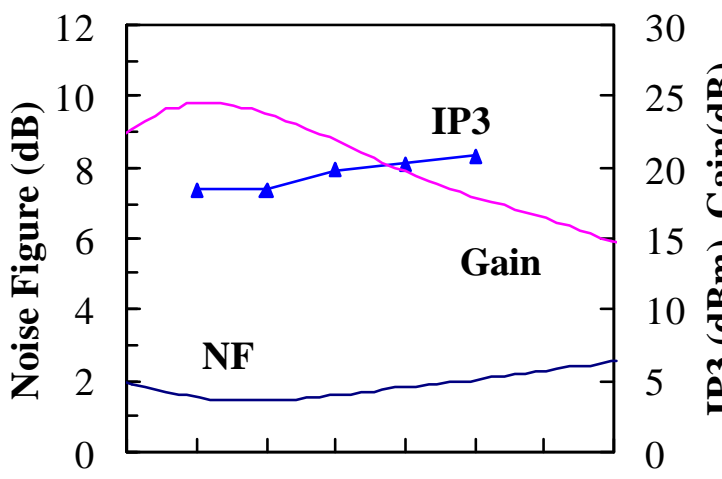

$\begin{array}{llllllll}22 & 24 & 26 & 28 & 30 & 32 & 34 & 36\end{array}$

FREQ.(GHz)

Figure 4. NF, Gain and IP3

Figure 5 shows output third order intercept point (IP3) of $20 \mathrm{dBm}$ with input signals at 30 and $30.01 \mathrm{GHz}$, at $\mathrm{V}_{\mathrm{DD}}=3 \mathrm{~V}$ and $\mathrm{I}_{\mathrm{DD}}=23 \mathrm{~mA}$ bias condition.

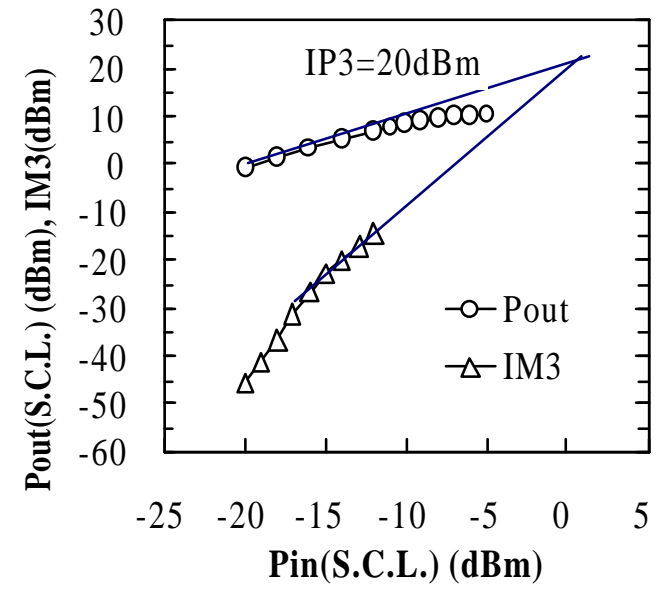

Figure 5. output power and IM3 versus
It was measured with RF-probe under $\mathrm{CW}$ RF drive. The third order inter-modulation distortion (IM3) product varies with a slope that remains approximately 3 , up to a relatively saturated power level. Here output power at $1-\mathrm{dB}$ compression $(\mathrm{P} 1 \mathrm{~dB})$ is $8.5 \mathrm{dBm}$ and small-signal gain is 19.3 $\mathrm{dB}$ under single-tone condition. IP3 is higher than $18.5 \mathrm{dBm}$ from 24 to 32 GHz (Figure 4). Figure 6 shows IM3 (in $\mathrm{dBc}$ ) versus the total output power level at the same bias condition.

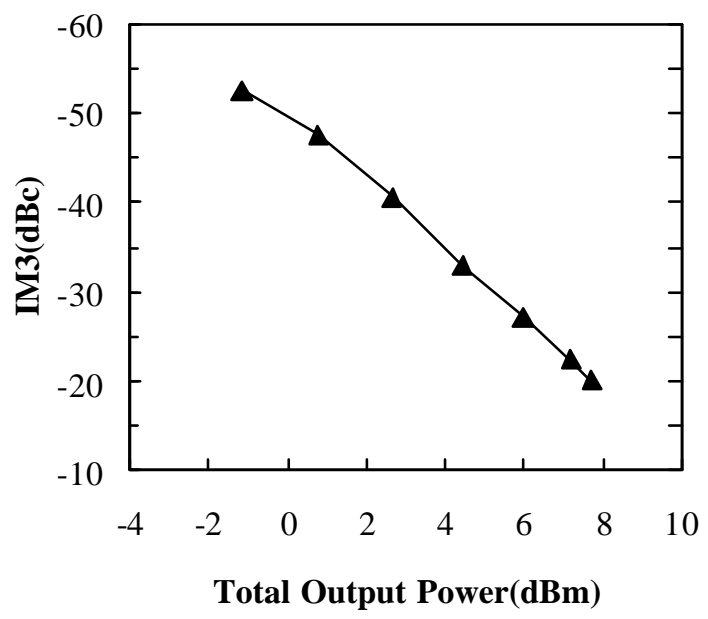

Figure 6. IM3 versus total output

The IM3 is better than $-45 \mathrm{dBc}$ at the total output power of $2 \mathrm{dBm}$. By means of extra source inductance, IM3 is $6 \mathrm{~dB}$ better than without source inductance.

\section{CONCLUSIONS}

We have developed an excellent noise figure and high linearity K-band 
p-HEMT LNA MMIC. Using single-bias configuration and negative feedback elements, the noise figure is lower than $2 \mathrm{~dB}$ and associated gain is more than $18 \mathrm{~dB}$ from 24 to $32 \mathrm{GHz}$. The IM3 is $-45 \mathrm{dBc}$ at the total output power of $2 \mathrm{dBm}$ and IP3 is $20 \mathrm{dBm}$ at $30 \mathrm{GHz}$. From these results, the LNA MMIC is suitable for high-speed wireless access system.

\section{ACKNOWLEGMENT}

The authors would like to thank Mr. K. Nakamura, Mr. K. Sakamoto and Mr. A. Ohtsuka for continuous encouragement throughout this work.

\section{REFERENCES}

[1] R.Gupta et al, "Fully monolithic CMOS RF power amplifiers: Recent advances", IEEE Commun, Mag., pp.84-97, April 1999.
[2] T.Saito et al, "60GHz MMIC Image-rejection downconverter using InGaP/InGaAs HEMT" IEEE GaAs IC Symposium Digest, pp.222-225, 1995.

[3] T.Hirose et al, "A Flip-Chip MMIC Design with Coplanar Theory and Tech., Vol. MTT-46, No.12, pp.2276-2282, December 1998.

[4] Y.Mimino et al, "An X-, K-Band Low-Noise P-HEMT MMIC Amplifier with Minimized Chip-Size by Using Smart Biasing and Matching Circuits" Asia-Pacific Microwave Conference Proc. pp. 391-394, 1998.

[5] Y.Mimino et al, "High Gain-density $\mathrm{K}$-band p-HEMT LNA MMIC for LMDS and Satellite Communication", IEEE MTT-S IMS Digest, pp.17-20, 2000. 